\title{
Modelling of emergency modes with FACTS devices installed
}

\author{
Alexey Udaratin ${ }^{1, *}$, Kirill Loginov ${ }^{1}$, Alexandr Nemirovskiy $^{1}$, Natalia Rozhentsova $^{2}$ and Elena Gracheva ${ }^{2}$ \\ ${ }^{1}$ Vologda State University, Lenina str. 15, Vologda, Russia \\ ${ }^{2}$ Kazan State Energy University, Krasnoselskaya str. 51, Kazan, Russia
}

\begin{abstract}
This paper considers installation of FACTS devices in a $500 \mathrm{kV}$ line of substation (SS) Belozerskaya - SS Vologodskaya. Three FACTS devices in emergency mode were modelled: a static reactive power compensator (STATCOM), a static synchronous series compensator, and a unified power flow control system. The parameters of MATLAB Simulink blocks were shown. The obtained results are summarized in Table, which substantiates the choice of the best device for the Belozerskaya Vologodskaya line in emergency mode.
\end{abstract}

\section{Introduction}

Electricity is an integral part of our modern world. It helps us to use a variety of electrical devices that make the life more comfortable.

However, the development of electrical power grids inevitably leads to two problems. Firstly, the resulting complex-closed and multi-level system cannot function without rigid control mechanisms (auto-control). Secondly, further development of the system requires involvement of new lands, which, given the introduction of private ownership of land, turns out to be very expensive. Under the current conditions, the Smart Grid ideology enabling controllability and increased transmission ability of grids is very promising. A number of experts claim that increasing the controllability of grids is a low-budget alternative to building new power lines. Actually, recently the transition to controlled grids has become an officially announced policy of the Russian network engineers. Active electro-technical network equipment (FACTS) is capable of flexibly change the characteristics of electric power transmission or conversion in order to optimize grid modes at once according to several criteria: throughput, technological loss level, stability, redistribution of power flows, power quality, etc. [1]

FACTS devices enable not only successful compensation of reactive power in the power grid, but also adequate response to abnormal conditions in it. Thanks to these parameters, flexible AC transmission systems are one of the best devices to be installed in line.

\section{Parameters of power system units}

The $500 \mathrm{kV}$ power system of substation (SS) Belozerskaya - SS Vologodskaya was modelled in the MATLAB Simulink program. It allows one to use various blocks to simulate the process of electric power transmission.
A three-phase short circuit is simulated using the Three-phase Fault block. It implements an error (short circuit) between any phase and ground. When the external switching time mode is selected, the logic signal Simulink is used to control the failure operation. The data are shown in Table 1.

Table 1. Three-phase failure characteristics.

\begin{tabular}{|l|c|}
\hline \multicolumn{1}{|c|}{ Parameter } & Value \\
\hline Switching time & {$[0.10 .30 .5] \mathrm{c}$} \\
\hline Failure resistance & $200 \mathrm{Ohm}$ \\
\hline Ground resistance & $0.001 \mathrm{Ohm}$ \\
\hline Shock absorber resistance & $1 \mathrm{MOhm}$ \\
\hline
\end{tabular}

The reactive power compensation is modelled using 3 blocks: Static Synchronous Compensator, Static Synchronous Series Compensator and United Power Flow Controller (Universal Energy Flow Control).

In MATLAB Simulink, these models are presented in two forms: Phasor model (a regular model that adjusts the main parameters of device) and Detailed mode (a model that allows one to configure devices for power compensation in more detail).

Static Synchronous Compensator (STATCOM) is one of the key FACTS devices. Based on a voltage converter, STATCOM regulates system voltage by absorbing or generating reactive power. Unlike a thyristor-based static variable compensator (SVC), the output current of the STATCOM (inductive or capacitive) can be controlled regardless of AC system voltage [2].

STATCOM parameters are shown in Table 2.

\footnotetext{
* Corresponding author: alexu79@mail.ru
} 
Table 2. STATCOM parameters.

\begin{tabular}{|l|c|}
\hline \multicolumn{1}{|c|}{ Parameter } & Value \\
\hline $\begin{array}{l}\text { Rated voltage and rated frequency of the } \\
\text { system }\end{array}$ & $\begin{array}{c}500 \mathrm{kV} \\
50 \mathrm{~Hz}\end{array}$ \\
\hline Rated power of compensator & $100 \mathrm{MVa}$ \\
\hline Rated resistance of compensator & $\begin{array}{c}{[0.22 / 30,} \\
0.22] \mathrm{r} . \mathrm{u} .\end{array}$ \\
\hline The initial value and phase of line current & {$[0,0]$} \\
\hline DC circuit rated voltage & $40 \mathrm{kV}$ \\
\hline Equivalent capacitance of DC circuit & $750 \mathrm{mF}$ \\
\hline $\begin{array}{l}\text { Maximum change rate of reference } \\
\text { voltage }\end{array}$ & 10 r.u./s \\
\hline $\begin{array}{l}\text { Difference between STATCOM } \\
\text { reference voltage and bus voltage }\end{array}$ & 0.03 \\
\hline Gain of boost voltage regulator & {$[51000]$ r.u. } \\
\hline Gain of DC voltage regulator & {$\left[\begin{array}{c}0.1 \mathrm{e}-320 \mathrm{e}- \\
3] \text { r.u. }\end{array}\right.$} \\
\hline Current gain & {$\left[\begin{array}{c}0.310 ~ 0.22] \\
\text { r.u. }\end{array}\right.$} \\
\hline
\end{tabular}

Static synchronous series compensator (SSSC), one of the key FACTS devices, consists of a voltage converter and a transformer connected in series with electric power transmission line. SSSC supplies a variable voltage quadratically to the line current, thereby simulating inductive or capacitive reactance. This emulated alternating reactance in series with the line may further affect the transmitted electric power. SSSC is used to suppress power fluctuations in electrical grid after a three-phase fault. [3]

The characteristics of SSSC are shown in Table 3.

Table 3. The characteristics of SSSC.

\begin{tabular}{|l|l|}
\hline \multicolumn{1}{|c|}{ Parameter } & \multicolumn{1}{c|}{ Value } \\
\hline $\begin{array}{l}\text { Rated voltage and rated frequency of the } \\
\text { system }\end{array}$ & $\begin{array}{l}500 \mathrm{kV} \\
50 \mathrm{~Hz}\end{array}$ \\
\hline Rated power of series compensator & {$[100,0.1] \mathrm{MVa}$} \\
\hline Rated resistance of compensator & $\begin{array}{l}{[0.22 / 30,0.22]} \\
\text { r.u. }\end{array}$ \\
\hline $\begin{array}{l}\text { The initial value and phase of line } \\
\text { current }\end{array}$ & {$[0,0]$} \\
\hline DC circuit rated voltage & $40 \mathrm{kV}$ \\
\hline Equivalent capacitance of DC circuit & $750 \mathrm{mF}$ \\
\hline $\begin{array}{l}\text { Maximum change rate of reference } \\
\text { voltage }\end{array}$ & 3 r.u./s \\
\hline $\begin{array}{l}\text { Difference between STATCOM } \\
\text { reference voltage and bus voltage }\end{array}$ & 0.03 \\
\hline Gain of boost voltage regulator & {$[0.031 .5] / 8$ r.u. } \\
\hline Gain of DC voltage regulator & $\begin{array}{l}{[0.1 \mathrm{e}-3 \quad 20 \mathrm{e}-3]} \\
\text { r.u. }\end{array}$ \\
\hline
\end{tabular}

Unified power flow control (UPFC) systems have advantages in terms of static and dynamic operation of the power system. It also poses new challenges in the field of power electronics and power system design. The basic structure of UPFC consists of two voltage source inverters (VSI); where one converter is connected in parallel with the transmission line (STATCOM), and the other is connected in series with the transmission line (SSPK). [4]

UPFC parameters are shown in Table 4.
Table 4. UPFC parameters.

\begin{tabular}{|c|c|}
\hline Parameter & Value \\
\hline $\begin{array}{l}\text { Rated voltage and rated frequency of the } \\
\text { system }\end{array}$ & $\begin{array}{l}500 \mathrm{kV} \\
50 \mathrm{~Hz}\end{array}$ \\
\hline Rated power of compensator & $100 \mathrm{MVa}$ \\
\hline Rated resistance of static compensator & $\begin{array}{l}{[0.22 / 30,0.22]} \\
\text { r.u. }\end{array}$ \\
\hline $\begin{array}{l}\text { The initial value and phase of line } \\
\text { current }\end{array}$ & {$[0,0]$} \\
\hline Rated power of series compensator & {$[100,0.1] \mathrm{MVa}$} \\
\hline Rated resistance of series compensator & $\begin{array}{l}{[0.22 / 30,0.22]} \\
\text { r.u. }\end{array}$ \\
\hline $\begin{array}{l}\text { The initial value and phase of line } \\
\text { current }\end{array}$ & {$[0,0]$} \\
\hline DC circuit rated voltage & $40 \mathrm{kV}$ \\
\hline Equivalent capacitance of DC circuit & $750 \mathrm{mF}$ \\
\hline $\begin{array}{l}\text { Maximum change rate of STATCOM } \\
\text { reference voltage }\end{array}$ & 0.1 r.u./s \\
\hline $\begin{array}{l}\text { Difference between STATCOM } \\
\text { reference voltage and bus voltage }\end{array}$ & 0.03 \\
\hline Gain of boost voltage regulator & [5 1000] r.u. \\
\hline Gain of DC voltage regulator & $\begin{array}{l}{[0.1 \mathrm{e}-320 \mathrm{e}-3]} \\
\text { r.u. }\end{array}$ \\
\hline Current gain & [0.5 25]/3 r.u. \\
\hline $\begin{array}{l}\text { Gain of boost voltage regulator of series } \\
\text { compensator }\end{array}$ & {$\left[\begin{array}{lll}0.025 & 1.5\end{array}\right]$ r.u. } \\
\hline
\end{tabular}

\section{FACTS in emergency mode}

\subsection{Modelling of STATCOM in emergency mode}

We simulate a three-phase short circuit using ThreePhase Fault. This is a three-phase fault unit that allows one to simulate various faults. The short circuit time is set so that it occurs at $\mathrm{t}=0.1-0.3$ and $\mathrm{t}=0.5-1$ seconds and disconnects the line for 0.15 seconds. Consider the graphs of three periods: the first short circuit at $\mathrm{t}=0.1-0.3$ $\mathrm{s}$, system recovery at $\mathrm{t}=0.2-0.4 \mathrm{~s}$ and the second short circuit at $\mathrm{t}=0.5-1 \mathrm{~s}$.

Fig. 1 presents the power system, Fig. 2 presents voltage, and Fig. 3 presents the active and reactive power during short circuit.

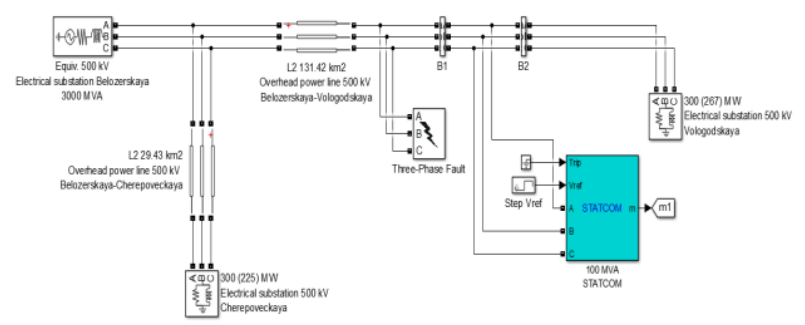

Fig. 1. Model of $500 \mathrm{kV}$ SS Belozerskaya - SS Vologodskaya power system with STATCOM device with Three-Phase Fault block. 


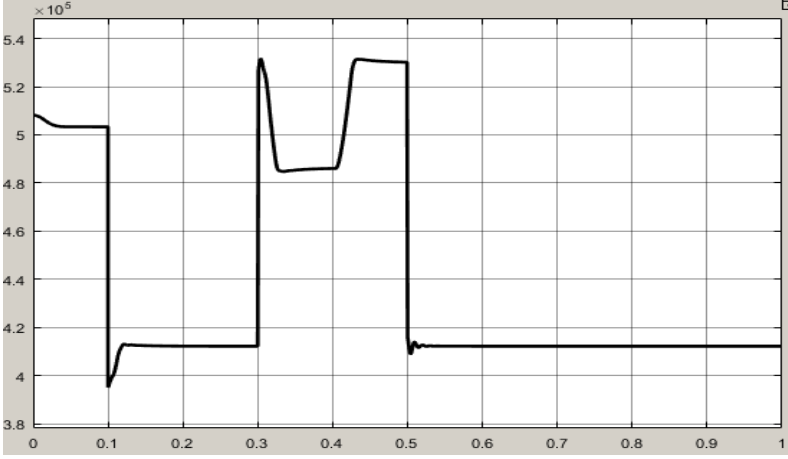

Fig. 2. Voltage on bus B1 with STATCOM device in emergency mode.

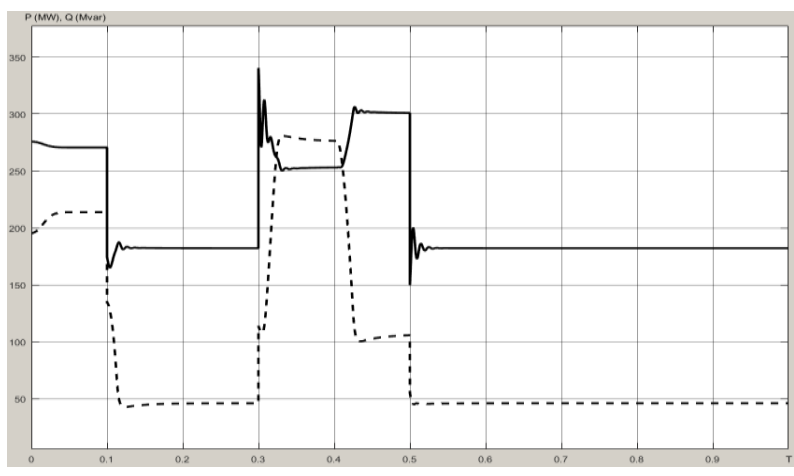

Fig. 3. Active and reactive power of line on B1 bus in the STATCOM emergency mode.

As it can be seen from graphs, after a short circuit at $\mathrm{t}=0.1-0.3 \mathrm{~s}$ and $\mathrm{t}=0.5-1 \mathrm{~s}$, the line voltage decreases. When STATCOM is operating in normal mode, then at $\mathrm{t}=0.2-0.4 \mathrm{~s}$, when the line voltage drops and power decreases, the reactive power increases to compensate losses, whereas for the emergency mode it decreases together with active power. When the system is restored to $\mathrm{t}=0.3$, the network voltage instantly rises to $530 \mathrm{kV}$ and then decreases to 490 , along with it the active power drops. STATCOM at this moment is trying to compensate it by its reactive power, increasing it in the system and returning it to its normal value. [5]

\subsection{Modelling of SSSC in emergency mode}

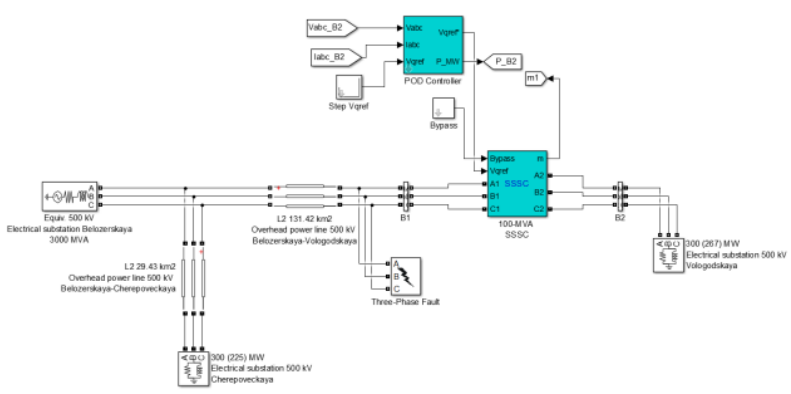

Fig. 4. Model of $500 \mathrm{kV}$ SS Belozerskaya - SS Vologodskaya power system with SSSC device with Three-Phase Fault block.

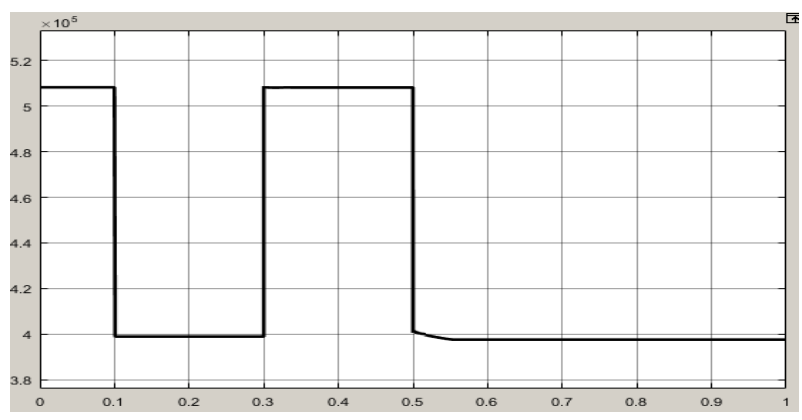

Fig. 5. Voltage on bus B1 with SSSC device in emergency mode.

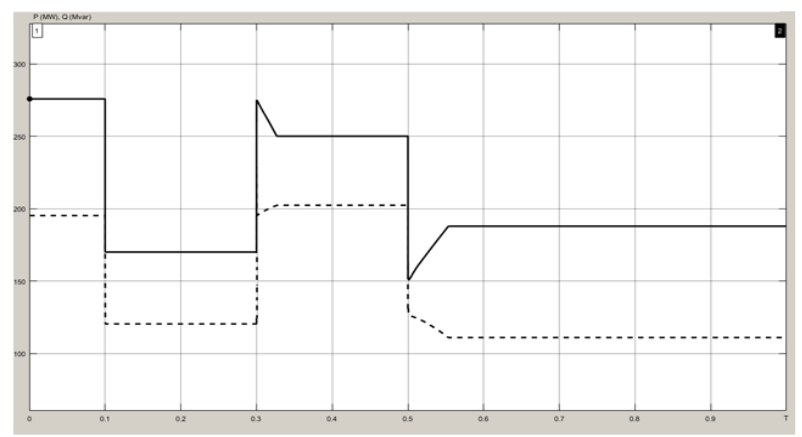

Fig. 6. Active and reactive power of line on B1 bus in the SSSC emergency mode.

Unlike STATCOM, the SSSC voltage practically does not change and drops only during a short circuit. The device operation during short circuit is not very different from its normal mode. During the first short circuit at $\mathrm{t}=0.1-0.3 \mathrm{~s}$, both powers decrease together with voltage, while the reactive power in this section decreases less than with STATCOM. Then, at $\mathrm{t}=0.2-0.4$ $\mathrm{s}$, the series compensator decreases the active power and slightly increases the reactive one. However, unlike STATCOM and UPFC, the device continues to work as in normal mode, at $\mathrm{t}=0.5-1 \mathrm{~s}$, reducing reactive power and increasing the active one. [6]

The power transmission line with SSSC in short circuit is shown in Fig. 4, and the voltage during short circuit is shown in Fig. 5. Active and reactive powers are shown in Fig. 6.

\subsection{Modelling of UPFC in emergency mode}

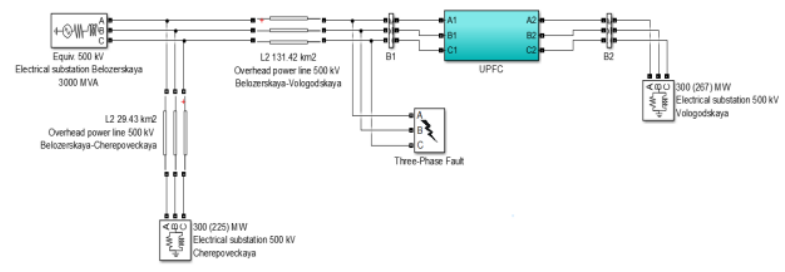

Fig. 7. Model of 500 kV SS Belozerskaya - SS Vologodskaya power system with UPFC device with Three-Phase Fault block. 


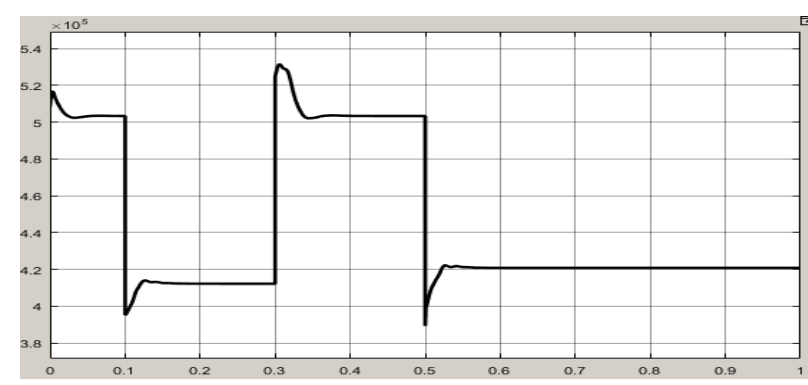

Fig. 8. Voltage on bus B1 with UPFC device in emergency mode.

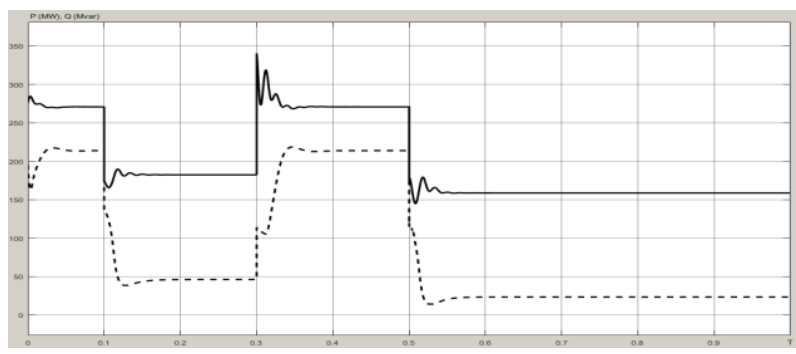

Fig. 9. Active and reactive power of line on B1 bus in the UPFC emergency mode.

The general UPFC operation principle during a short circuit is similar to the operation of static synchronous and static series compensators. It should be noted that the energy flow control system is most sensitive to voltage drops among the all devices. [7] At $\mathrm{t}=0.1-0.3 \mathrm{~s}$, voltage decreases, and active and reactive power decreases. At $\mathrm{t}=0.2-0.4 \mathrm{~s}$, an increase in reactive power occurs, without a decrease in active power. At $\mathrm{t}=0.5-1 \mathrm{~s}$ together with a decrease in voltage, the reactive power decreases along with the active one. [8]

The system is shown in Fig. 7. The voltage on bus B1 is shown in Fig. 8. Short-circuit capacities are shown in Fig. 9.

\section{Conclusions}

The performed modelling shows that FACTS devices act differently in emergency mode, in contrast to the normal mode. Using the data listed in Table 5, one can find out how the work could be continued and the reactive power could be compensated using compensations during abnormal mode. Successful power compensation consists of increasing active power and reducing reactive losses in power grid. [9] Two short circuits occur in this system, and a short recovery period. Using it, one can measure the active and reactive power, calculate the average values for each of the devices, and choose the most suitable one.
Table 5. Comparison of $Q$ and $P$ on bus $B 1$ of FACTS devices with short circuits.

\begin{tabular}{|c|c|c|c|c|c|c|}
\hline 次产 & $\begin{array}{c}\text { Q, MVAr } \\
\text { STATCO } \\
\text { M }\end{array}$ & $\begin{array}{c}\text { P, MW } \\
\text { STATCO } \\
\text { M }\end{array}$ & $\begin{array}{c}\text { Q, } \\
\text { MVA } \\
\mathbf{r} \\
\text { SSSC }\end{array}$ & $\begin{array}{c}\text { P, } \\
\text { MW } \\
\text { SSS } \\
\text { C }\end{array}$ & \begin{tabular}{|c|} 
Q, \\
MVA \\
r \\
UPF \\
C
\end{tabular} & \begin{tabular}{|} 
P, \\
MW \\
UPF \\
C
\end{tabular} \\
\hline 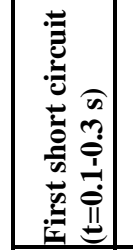 & 50 & 175 & 125 & 175 & 49 & 175 \\
\hline 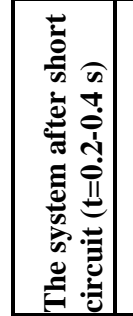 & 187.5 & 275 & 200 & 250 & 220 & 275 \\
\hline 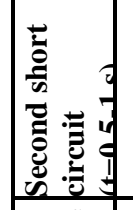 & 50 & 175 & 115 & 185 & 25 & 155 \\
\hline 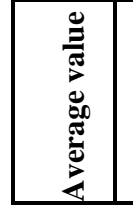 & 95.8 & 208.3 & 146.6 & $\begin{array}{c}203 . \\
3\end{array}$ & 98 & 201.6 \\
\hline
\end{tabular}

The table, created using experimental results, shows how much FACTS devices reduce reactive power and increase active power. The static synchronous compensator shows the best performance, with an active power of 208.3 MW and a reactive power of 95.8 MVAr.

\section{References}

[1] A. Udaratin, A. Alyunov, A. Krutikov, L.R. Mukhametova, O.O. Zaripov, I.V. Bochkarev, E3S Web of Conferences 124, 02020 (2019).

[2] A. Nemirovskiy, A. Kashin, V. Kosmach, Y. Titovec, I. Toptygin, D. Zaripova, IOP Conference Series: Earth and Environmental Science (EES) 337, 1, 012071 (2019).

[3] A. Ydaratin, T. Akhmetov, S. Makoev, IJCIET 10, 2, (2019).

[4] V. Zhukov, A. Shmelev, D. Mikheev, Russian Electrical Engineering 89, 5 (2018).

[5] M. Bashirov, A. Khismatullin, E. Sirotina, LNEE 641, 613-621 (2020).

[6] S. Tsyruk, S. Gamazin, Y. Ryzhkova, K. Charafeddine, Dynamics, 8601484 (2019).

[7] V. Kozlovsky, S. Petrovsky, V. Vakhnina, D. Skripnuk, EIConRus, 8657322, 569-573 (2019). 
[8] E. Gracheva, O. Fedorov, Forecasting Reliability Electrotechnical Complexes of In-Plant Electric Power Supply Taking into Account LowVoltage Electrical Apparatuses, ICIEAM 5 (2019).

[9] V. Ivanova, I. Ivanov, N. Rozhentsova, Justification of the set of technical and technological criteria when designing a combined power supply system for multi-story residential buildings, ICOECS 2019, 8949983 (2019). 